RU Намек в немецком кинодискурсе: реакция адресата

Штукатурова Е. П.

\begin{abstract}
Аннотация. Цель исследования - рассмотреть различную реакцию адресата на намек в немецком кинодискурсе с учетом условий коммуникации. В статье принимается во внимание тип адресата, а также факт наличия/отсутствия третьего лица при коммуникации. Верная интерпретация намека со стороны адресата зависит от множества факторов. Одной из наиболее важных предпосылок для понимания намека является наличие идентичного кода у адресанта и адресата. Научная новизна исследования заключается в создании типологии реакции адресата на намек в современном немецком кинодискурсе. В результате исследования выделено два типа реакции: понимание намека без уточнения и с уточнением имплицитного иллокутивного акта адресанта. Также обнаружен пример, в котором адресат интерпретирует прямое высказывание как намек. Это дает основание для рассмотрения еще одного типа реакции в дальнейшем исследовании.
\end{abstract}

\title{
EN A Hint in the German Film Discourse: The Addressee's Reaction
}

\section{Shtukaturova E. P.}

Abstract. The paper examines the addressee's various reactions to a hint in the German film discourse, taking into consideration communication conditions. The paper takes into account the type of the addressee, as well as whether there is a third party present during communication or not. The correct interpretation of a hint by the addressee depends on many factors. One of the most important prerequisites for the understanding of a hint is that the addresser and the addressee have the same code. Scientific originality of the study lies in creating a typology of the addressee's reaction to a hint in the modern German film discourse. As a result of the study, two types of reaction have been identified: understanding a hint without clarification and with clarification of the addresser's implicit illocutionary act. The researcher has also found an example in which the addressee interprets a direct statement as a hint. This allows for consideration of another type of reaction in a further study.

\section{Введение}

В современном мире влияние кинематографа на человека неоспоримо велико. Просмотр кинофильмов является популярным видом досуга. Актуальность исследования обусловлена тем, что в кинофильмах проявляются культурные особенности общества в прошлом и на современном этапе развития, находят отражение национальная ментальность и национальная языковая картина мира, представляется актуальное речевое общение с определенными стратегиями и тактиками.

Для достижения указанной цели исследования необходимо решить следующие задачи: во-первых, выявить скрытое содержание намека; во-вторых, определить тип адресата; в-третьих, проанализировать условия коммуникации.

В качестве основных методов исследования используются метод сплошной и направленной выборки, интерпретативный метод, а также метод контекстного анализа, в рамках которого учитываются экстралингвистические характеристики коммуникации.

Материалом исследования послужили кинодиалоги из фильмов и сериалов немецкого производства XXI в. (https://www.onleihe.de/goethe-institut; https://www.netflix.com).

Теоретическую базу исследования составили работы отечественных и зарубежных авторов, в которых рассматриваются проблемы лингвопрагматики (Почепцов, 1986; Grice, 1991), а также особенности намека (Кобозева, Лауфер, 1988), кинодискурса (Зарецкая, 2008; 2010) и кинодиалога (Горшкова, 2006).

Практическая значимость исследования заключается в том, что рассмотренные в статье ситуации намека и реакции адресата на намек могут быть использованы при обучении дисциплинам, посвященным межкультурной коммуникации и культуре речевого общения на немецком языке. 


\section{Основная часть}

Отечественный лингвист А. Н. Зарецкая (2010) определяет кинодискурс как креолизованный текст, обладающий свойствами «целостности, связности, информативности, коммуникативно-прагматической направленности, медийности» (с. 5). Благодаря вербальному компоненту кинофильма - связному тексту - представляется возможным корректное декодирование сообщения (с. 5).

А. Н. Зарецкая $(2008 ; 2010)$ также занимается разработкой проблемы роли подтекста в кинодискурсе. Она подчеркивает обязательное наличие эксплицитной и подтекстовой информации в кинодискурсе.

Вслед за В. Е. Горшковой (2006) мы используем в работе термин «кинодиалог», под которым понимается «квазиспонтанный разговорный текст, подвергшийся определенной стилизации в соответствии с художественным замыслом режиссера и ориентированностью на особый кинематографический код, что находит свое выражение в доминировании диалогической формы речи персонажей как первичной, естественной формы речевого общения» (с. 5).

В кинодиалогах адресант и адресат - это говорящий и слушающий, а способ передачи сообщения - устная речь. В целом возникает имитация ситуации непосредственного бытового общения, в ходе которого говорящие обмениваются репликами. В рамках такого общения часто используются намеки. Намек - это один из видов косвенного речевого акта, в котором истинный, имплицитный иллокутивный акт осуществляется косвенно, через реализацию другого, эксплицитного иллокутивного акта (далее - ИА), при этом смена иллокуции сопровождается сменой пропозиции. В кинодиалоге намек может быть проанализирован на уровне иллокуции, локуции и перлокуции.

Реакция на намек во многом связана с типом адресата. Адресатом, по определению Г. Г. Почепцова (1986), является лицо или группа лиц, которому/которой предназначается речевой акт говорящего. Г. Г. Почепцов выделяет два типа косвенной адресатности: последовательная (говорящий -> адресат-ретранслятор -> истинный адресат) и параллельная (говорящий -> прямой адресат, косвенный адресат). Двуадресатность высказывания, описанная Г. Г. Почепцовым, представляет для нас особый интерес в ситуациях намека.

Косвенным адресатом является присутствующий при диалоге адресанта с прямым адресатом слушающий, которому по факту предназначено высказывание. В данном случае адресант использует более сложный механизм создания намека, чем в ситуации общения без участия косвенного адресата, так как эксплицитный и имплицитный ИА адресованы разным коммуникантам.

Согласно критерию выводимости, рассмотренному в качестве одной из базовых характеристик прототипического намека в работе (Кобозева, Лауфер, 1988), говорящий должен сформулировать высказывание таким образом, чтобы адресат мог вывести ту информацию, которую подразумевал адресант. Для этого адресант и адресат должны обладать идентичными кодами (Лотман, 1996, с. 13-14). Следует отметить, что адресат может как не увидеть в высказывании заложенного говорящим скрытого смысла, так и обнаружить намек там, где его нет.

Далее приводятся 2 типа реакции адресата на намек. При этом типы конкретизуются по критерию наличия/отсутствия третьего лица, типу дискурса с позиций коммуникантов: личностно- или статусно-ориентированный дискурс (Карасик, 2002, с. 199), типу адресата в классификации Г. Г. Почепцова, тематике намека, определяемой по содержанию имплицитного ИА.

В каждом подтипе приводится по одному примеру кинодиалога, содержащему намек. Кинодиалоги протекают между людьми, связанными любовными, семейными, дружескими и кооперативными отношениями. Намеки выделяются подчеркиванием, в скобках дается возможный вариант невербализованной ситуации.

\section{1. Понимание намека без уточнения имплицитного ИА адресанта}

К данному типу относятся намеки, при которых адресат без уточнения интенции адресанта понимает имплицитный смысл высказывания и реагирует в соответствии с ним.

\section{1. Прямой адресат}

Источник примера - немецкий телесериал “Dark” (2017-2020 гг.). Условия коммуникации: жена скрывает от мужа, что у нее обнаружен рак 4 стадии. Муж звонит в маммологический центр, чтобы получить информацию об обследовании. Ему сообщают, что результаты были высланы вчера: на снимках обнаружены метастазы. Он сразу звонит жене:

(1) - Wann kommst du nach Hause? / Когда ты будешь дома?

- Gleich... / Скоро.

- $\quad$ (колеблется) Ich bin immer für dich da, das weißt du. Egal, was passiert. Komm nicht zu spät. (Es tut mir leid, dass du Metastase hast.) / Ты знаешь, что я всегда с тобой. Что бы ни случилось. Не задерживайся. (Мне жаль, что у тебя метастазы.)

- $\quad$ (со слезами на глазах) Okay. / Хорошо (здесь и далее перевод выполнен автором статьи. - E. Ш.).

Имплицитный ИА: адресант выражает сочувствие к адресату в его нынешнем положении. Эксплицитный ИА: адресант предлагает помощь.

Адресант спешит поддержать адресата. Повод для звонка - узнать, когда адресат вернется домой. Для такого разговора не типично выражение готовности оказать поддержку, поэтому адресат понимает интенцию адресанта «выразить сочувствие адресату». Слезы являются невербальным маркером понимания намека.

\section{2. Косвенный адресат}

Источник примера - фильм “Da geht noch was” (2013 г.). Условия коммуникации: у мужчины было несчастливое детство. Отец, по его мнению, издевался над ним. Повзрослев, сын навещал родителей раз в год 
в день рождения матери. Спустя 40 лет совместной жизни брак родителей распадается: мать уходит от отца. По стечению обстоятельств сын оказывается рядом с отцом, когда тот получает травму. Мужчина проводит собеседование с домработницей для отца. Рядом с ним на диване сидит его отец с костылем в руке. Во время приведенной ниже части собеседования отец не произносит ни слова. В итоге домработницу не нанимают.

(2) - Nach der Wende saß ich drei Monate wegen der Dopings, Steroiden. Haben Sie damit ein Problem? / После падения [Берлинской] стены я сидела три месяца в тюрьме из-за использования допинга. Это Вас не смущает?

- Ü̈berhaupt nicht, Frau Michels. / Ничуть, госпожа Михельс.

- $\quad$ Ach ja, dann noch zwei Jahre wegen angeblicher Misshandlung vom Pflegebedürften. / Ах, да, потом еще два года из-за недоказанного избиения подопечного.

- $\quad$ Wann können Sie anfangen? (Das hast du verdient.) / Kогда Вы сможете приступить? (Ты это заслужил.) Отец бьет по ноге сына костылем.

Имплицитный ИА: адресант негативно относится к действию косвенного адресата в прошлом. Эксплицитный ИА: адресант узнает у адресата о времени начала гипотетической ситуации.

В вербализованной ситуации адресант интересуется возможностями адресата, на самом деле он не желает получить ответ на свой вопрос, так как ему не важна запрашиваемая информация. Тем самым он нарушает первую субмаксиму качества (Grice, 1991). Адресант озвучивает следствие Wann können Sie anfangen? / Koгдa можете начать? и умалчивает причину. Причин - невербализованных ситуаций - оказывается две. Адресат (домработница) выведет причину: Sie bekommen die Stelle. / Bы приняты на работу. Вопрос о времени, когда кандидат на вакансию может начать работу, является конвенциональным косвенным речевым актом. Слушающий (отец), он же косвенный адресат, увидит иную причину: Das hast du verdient. / Tы это заслужил. Адресант мстит слушающему за прошлое в шутку, так как в действительности он не нанимает домработницу. Вопрос, заданный адресату, является риторическим и служит средством выражения намека. Намерение говорящего изменить эмоциональное состояние слушающего дает основание относить данный пример к намеку. Кроме того, невербальная реакция косвенного адресата подтверждает факт наличия намека.

\section{2. Понимание намека с уточнением имплицитного ИА адресанта}

Нередко адресат намеренно уточняет интенцию адресанта или вербализует имплицитный ИА. Данная реакция возникает по ряду причин: адресата сильно удивила или возмутила услышанная информация, адресат хочет быть полностью уверен в выведенной скрытой информации. Уточнение может быть сформулировано в форме вопроса с глаголами мысли и речи meinen, sagen, к примеру, Wie meinst du das? (Что ты uмeешь в виду?) и Warum sagst du das? (Почему ты это говоришь?).

\section{1. Прямой адресат в отсутствии третьего лица}

Источник примера - фильм “Willkommen bei den Hartmanns“ (2016 г.). Условия коммуникации: мужчина попал в клинику и должен пробыть там некоторое время. Чтобы избежать нахождения в клинике, он решает подкупить врача. Происходит диалог между пациентом и врачом. Интенция врача - «побудить адресата к даче более крупной взятки». Врач называет причину, по которой это необходимо сделать:

(3) Пациент: 3000.

Врач: Ich habe 5 Kinder. (Ich will 5000 Euro.) / У меня 5 детей. (Я хочу получить 5 тысяч евро.)

Пациент (судорожно бросает взгляд на фотографии детей в кабинете, на фотографиях действительно 5 детей): 5000?

Имплицитный ИА: адресант сообщает о будущем выгодном для себя положении дел. Эксплицитный ИА: адресант сообщает личную информацию о себе.

В данном примере, относящемся к статусно-ориентированному дискурсу, нарушена максима отношения по Грайсу: адресант отклонился от темы разговора, чтобы скрыть факт побуждения к даче взятки. Механизм создания намека представлен логической цепочкой: адресат предложил адресанту 3000 евро. Этого недостаточно. Адресант во избежание возможных негативных последствий не называет желаемую сумму, а сообщает о количестве детей, которое равняется 5. 3000 и 5 являются числительными. 3000 содержит 3 единицы разряда тысяч, 5000 - это 5 единиц. Адресант заменяет единицы, намекая на размер взятки. Адресат озвучивает следствие, так как хочет быть уверен в успешности сделки.

\section{2. Прямой адресат в присутствии третьего лица}

Источник примера - фильм “Erbsen auf halb 6” (2004 г.). Условия коммуникации: ослепший в результате автоаварии мужчина разговаривает со своей девушкой в мужской уборной в присутствии незнакомого мужчины:

(4) - Vielleicht brauchst du Hilfe? Ich kann lernen dir zu helfen. / Возможно, тебе нужна помощь. Я могу научиться помогать тебе.

- $\quad$ Du brauchst es nicht zu lernen. (Ich will mich von dir trennen.) / Тебе не надо этому учиться. (Я намереваюсь расстаться с тобой.)

- Warum sagst du das? Du willst, dass wir uns trennen? / Что ты такое говоришь? Ты хочешь, чтобы мы расстались?

Якоб молчит. Девушка:

- Jakob! / Якоб!

- Ja. / Да.

- $\quad$ Warum willst du denn es nicht wenigstens versuchen? / Почему ты не хочешь хотя бы попробовать?

- Du kannst dich nicht von einem Blinden trennen. Du schaffst das nicht. Aber ich kann es. Ich kann mich von dir trennen. Lass mich. / Ты не сможешь бросить слепого. У тебя не получится. А я смогу. Я могу расстаться с тобой. Оставь меня. 
Имплицитный ИА: адресант сообщает о будущем выгодном для себя положении дел. Эксплицитный ИА: адресат не совершает действие в будущем.

Коммуникация протекает в присутствии третьих лиц, наличие слушающего оказывает влияние на речевое поведение адресанта: адресант заявляет косвенно о расставании, а после того, как адресат озвучивает верно понятый намек, медлит с ответом. Поднятая тема является важной для адресата, поэтому его не смущает ни место коммуникации (мужской туалет), ни наличие третьего лица - невольного свидетеля диалога.

Выделение третьего типа реакции адресата на намек, а именно интерпретации прямого высказывания как намек, возможно в случае бо́льшего количества примеров. На данный момент в немецком кинодискурсе нами обнаружен единственный пример, когда адресат трактует прямое высказывание как намек. В этом случае в скобках приводится та невербализованная ситуация, которую, по мнению адресата, подразумевал адресант.

Источник примера - фильм “3 Zimmer / Küche / Bad” (2012 г.). Условия коммуникации: новоселье. Дина говорит праздничную речь перед друзьями по поводу только что завершившегося переезда в новую квартиру. В это время в квартиру входит Мария вместе с Михаэлем. Мария опоздала, так как перепутала дом.

(5) Дина: Hey Maria, das is' Maria, die Freundin von meinem besten Freund. / Привет, Мария, это Мария, девушка моего лучшего друга.

Филипп: Und das is'... / A это...

Михаэль: Michael. Ich hab' sie nach hier gefahren. Sie war bei falschem Umzug. / Я привез ее сюда. Она попала не на то новоселье.

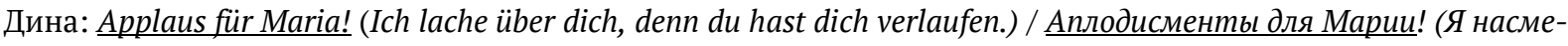
хаюсь над тобой, потому что ты заблудилась.)

Дина и кто-то из друзей за кадром аплодируют. Мария уходит.

Дина: Неy Maria, das war... das war nicht so gemeint. / Эй, Мария, я не... я не это имела в виду.

Имплицитный ИА (с позиции Марии): адресант негативно относится к действию адресата в прошлом. Эксплицитный ИА (с позиции Марии): адресант приветствует адресата и побуждает слушающих к тому же.

В пропозиции содержится побуждение группы слушающих к определенной поведенческой норме - аплодисментам. Оценочный смысл данного призыва в немецкой лингвокультуре не однозначен (одобрение, признание/насмешка) и интерпретируется адресантом и адресатом по-разному, что приводит к коммуникативной неудаче. Адресат расценивает высказывание Applaus für Maria как саркастическую насмешку, оскорбление и порицание. Предположительно, Мария является обидчивым и вспыльчивым человеком, так как она сразу же уходит из квартиры. Жидкие и разрозненные аплодисменты слушающих свидетельствуют о том, что они восприняли слова адресанта так же, как и адресат.

\section{Заключение}

В результате исследования реакции адресата на намек в немецком кинодискурсе сделаны следующие выводы.

В кинодискурсе адресанты используют намек в тех случаях, когда намерены выразить сочувствие адресату, раскритиковать/высмеять адресата или сообщить о личной выгоде. Намеки более характерны для личностно-ориентированного, чем для статусно-ориентированного дискурса.

В кинодиалогах адресат реагирует на намек как вербально, так и невербально. В большинстве случаев адресант строит высказывание в соответствии с критерием выводимости, что позволяет адресату правильно извлечь намек. Основанием для неверной интерпретации намека могут стать индивидуальные особенности адресата, например вспыльчивость. Роль третьего лица (слушающего) в ситуациях намека неоднородна: намек адресован слушающему; намек осуществляется, чтобы дискредитировать адресата в глазах слушающих; намек позволяет скрыть личную тему от слушающего.

Таким образом, в немецком кинодискурсе рассмотрены следующие типы реакций адресата на намек:

Тип 1. Понимание намека без уточнения имплицитного ИА адресанта.

Тип 2. Понимание намека с уточнением имплицитного ИА адресанта.

Перспективы дальнейшего исследования проблемы мы видим в более детальном изучении немецкого кинодискурса с целью дополнения типологии реакции адресата на намек и выявления лингвокультурных особенностей намека.

\section{Источники | References}

1. Горшкова В. Е. Теоретические основы процессоориентированного подхода к переводу кинодиалога (на материале современного французского кино): автореф. дисс. ... д. филол. н. Иркутск, 2006.

2. Зарецкая А. Н. Особенности реализации подтекста в кинодискурсе // Вестник Челябинского государственного университета. 2008. № 16 .

3. Зарецкая А. Н. Особенности реализации подтекста в кинодискурсе: автореф. дисс. ... к. филол. н. Челябинск, 2010.

4. Карасик В. И. Языковой круг: личность, концепты, дискурс. Волгоград: Перемена, 2002.

5. Кобозева И. М., Лауфер Н. И. Об одном способе косвенного информирования // Известия Академии наук СССР. Серия литературы и языка. 1988. Т. 47. № 5. 
6. Лотман Ю. М. Внутри мыслящих миров: человек - текст - семиосфера - история. М.: Языки русской культуры, 1996.

7. Почепцов Г. Г. О коммуникативной типологии адресата // Речевые акты в лингвистике и методике: сб. науч. тр. Пятигорск: ПГПИИЯ, 1986.

8. Grice H. P. Logic and Conversation // Grice H. P. Studies in the Way of Words. Cambridge - L.: Harvard University Press, 1991.

\section{Информация об авторах | Author information}

RU Штукатурова Елизавета Петровна ${ }^{1}$

${ }^{1}$ Российская академия народного хозяйства и государственной службы при Президенте РФ, г. Москва

EN Shtukaturova Elizaveta Petrovna ${ }^{1}$

${ }^{1}$ The Russian Presidential Academy of National Economy and Public Administration, Moscow

${ }^{1}$ elizaveta.shtukaturova@gmail.com

\section{Информация о статье | About this article}

Дата поступления рукописи (received): 13.12.2021; опубликовано (published): 28.02.2022.

Ключевые слова (keywords): намек; косвенный адресат; прямой адресат; имплицитный иллокутивный акт; кинодискурс; hint; indirect addressee; direct addressee; implicit illocutionary act; film discourse. 